\title{
Helen Salisbury: The perils of deprescribing
}

\author{
Helen Salisbury GP \\ Oxford
}

Imagine that my next patient is a 78 year old who's come about her back pain-it's no better, and she won't get the physiotherapy she needs for many weeks yet. She'd also like me to look at a funny mole on her back. I note that she has eight medicines on her repeat prescription list and is overdue a review. In our 12 minutes together I need to attend to her agenda but also to make sure that the cocktail of pills she's receiving is doing her more good than harm. Alas, the discussion we're likely to manage about each one will be along these lines: "Are you taking this one? Any problems?"-rather than the more detailed conversation I'd like to have about the indications for it and the risks and benefits. We'd then perhaps be able to rationalise her medication, reducing her risk and treatment burden, and saving some money too.

Apart from time, which I mostly don't have, what's stopping me? It's clear to me that many of my patients are taking too much medicine, but it's so much easier to start something than to stop it.

Using statins as an example, my patient may have had a QRISK calculation showing that her risk of a cardiovascular event was greater than $20 \%$ in the next 10 years despite being a non-smoker with normal blood pressure, no diabetes, and no family history. Someone (maybe me) will have explained that taking a statin tablet long term will help to prevent a stroke or heart attack. This may even have involved sharing a decision aid with her.

If I now tell her that she doesn't need it after all, what might she hear? That she's too old to be worth spending money on? That she hasn't long to live? That preventing her stroke or heart attack is no longer a priority in the cash strapped NHS? Or, possibly, that her previous doctor got it wrong.

\begin{abstract}
Many of my patients are taking too much medicine, but it's so much easier to start something than to stop it
\end{abstract}

I hope that I'll be able to tell her about new research ${ }^{1}$ showing that, as she's reached this age without having a heart attack or stroke, she's unlikely to benefit from cholesterol lowering medication. Some of my patients will be absolutely delighted to have one less pill to take; others will find this a difficult conversation, and they may feel a little less safe without their statin.

Perhaps we need to be more careful when starting medicines, to leave open the possibility that one day they should be stopped. We certainly need to build our confidence in how to have these conversations, to reduce the treatment burden on our patients and begin to tackle the huge waste of time and money that this overprescribing represents.

Competing interests: I am a GP partner, I teach medical students at Oxford University and St Anne's College, Oxford, and I answer readers' medical problems for Take A Break magazine. I am also a member of the National Health Action Party and serve on its national executive committee.

Provenance and peer review: Commissioned; not externally peer reviewed. bmj.com Editorials: Rationalising medications through deprescribing (BMJ 2019;364:I570, doi:10.1136/bmj.1570)

Ramos R, Comas-Cufí M, Martí-Lluch R, etal . Statins for primary prevention of cardiovascular events and mortality in old and very old adults with and without type 2 diabetes: retrospective cohort study. BMJ 2018;362:k3359. 10.1136/bmj.k3359 30185425

Published by the BMJ Publishing Group Limited. For permission to use (where not already granted under a licence) please go to http://group.bmj.com/group/rights-licensing/ permissions 